\title{
Bullying in Universities: A Qualitative Analysis of the Lived Experiences of Students
}

\author{
with Special Needs \\ * Sehrish, MPhil Scholar \\ ** Dr. Yaar Muhammad, Assistant Professor (Corresponding Author) \\ *** Dr. Faisal Anis, Assistant Professor
}

\begin{abstract}
Bullying has been known as an extensive, persistent, and severe problem in educational institutions across the globe. Despite the research studies on bullying in recent years, most of the research directly focused on its multiple slants and characteristics among students without special needs (SN). Besides, few research studies are known about bullying in universities and its dimensions in the population of students with SN receiving support provision. In light of the above, the present study explored the students' lived experiences related to bullying and victimization getting an education in universities with peers without SN. The sample of this phenomenological study consisted of 10 participants with SN attending university education. Semi-structured interviews were used as a research method for data collection. All participants shared negative experiences of bullying in universities while studying with students without SN.
\end{abstract}

Keywords: Lived Experiences; Bullying; Inclusive Universities; Students with Special Needs; Qualitative Research; Purposive Sampling; Thematic Analysis

\section{Introduction}

Bullying is a practice that hurts an individual's sentiments and emotions by intentional or unintentional acts or behavioral traits. This act of hurting, otherwise defined as external aggression, is also central and aggressive behavior is a conflict between two equal power-holding individuals (Olweus, 1994). Bullying, however, includes the human behavior of hurting someone less powerful and unable to protect oneself from that aggressive or humiliating behavior of another individual. Bullying is further defined as a repeated act of hurting and teasing someone multiple times. "A student is being bullied or victimized when he or she is exposed, repeatedly and over time, to negative actions on the part of one or more other students" (Olweus, 2001, pp. 5-6). Another quite similar definition states: "bullying is longstanding violence, physical or mental, conducted by an individual or a group and directed against an individual who is not able to defend himself in the actual situation" (Roland, 1989, p. 21). According to Rigby (1998), bullying can be seen into many different types such as verbal abuse, for example, taunting, attempts to ridicule, social abuse like dissemination of rumors, exclusion from groups, physical (pushing, kicking, hitting) further defined forms of bullying are racism and sexual abuse.

Besides, disability is believed to be a social process rather than an individual defect; disability exists in the despotism of everyday life, affecting every individual's life, regardless of whether they have any impairment, either physical, mental, or emotional (Rieser \& Mason, 1990; Graham, 2020). This observable act is intensifying that has been causing problems to the students with SN, their families, and also impacted the educational environment in the past years (Craig, Henderson, \& Murphy, 2000; Graham, 2020).

Bullying experiences of students with SN in educational institutes result in negative outcomes that decrease their confidence level and make them fearful of educational institutes. As per other research, students with diverse needs face amplified bullying oppression, including hidden and visible disabilities like developmental, physical, emotional, intellectual, and sensory disabilities (Carter \&

* Department of Education, University of Management and Technology, Lahore Email: sehrishrajput497@gmail.com

** Department of Education, University of Management and Technology, Lahore Email: Yaar.Muhammad@umt.edu.pk

*** Department of Education, University of Management and Technology, Lahore Email: Faisal.Anis@umt.edu.pk 
Spencer, 2006). Kourkoutas, Giovazolias, and Mitsopoulou (2007) stated that the phenomenon of bullying seems to relate directly to one out of three students with SN in many countries. Commonly seen issues of fear, disliking for school duration hours, annoyance, distraction, and removal from school are resulting factors of bullying that arises in the students with SN when they face any kind of bullying and are unable to guard them and also cannot have the courage to tell anyone like teachers or family. Increased absenteeism among students with SN is primarily due to bullying because of their fear of facing up to their oppressors. There is also the possibility that these children may become aggressive or tense under the circumstances of being bullied. At the same time, on other occasions, these victims may become bullies to other students afterward. (Klomek, Marrocco, Kleinman, Schonfeld, \& Gould, 2008). Many factors like age, gender, the socio-economic status of the family of the students, their residential locations (areas), and parental involvement can relate to the bullying with SN behavior (Klomek et al., 2008).

According to experts, bullying or aggressive behavior can not only be judged as a result of the conditions relating to the involvement of individuals due to several internal or external factors but also the wider environmental factors where they belong (Klomek et al., 2008). Due to the bullying in inclusive schools, many of the students with SN were separated from students without SN. Many recent studies showed that students with SN are getting more benefits while being in inclusive schools or universities rather than being separated, and accordingly, the segregated school system has been inefficient enough to prove their effectiveness (Klomek et al., 2008). Furthermore, not only the students with SN but also the students without SN can get benefits while studying in inclusive setups. Engaging instructional activities, level of interruption to planned activities, class grades class test scores are positively impacted in the case of students with SN getting normal education in inclusive setups with general students in a normal educational environment (Carter \& Spencer, 2006).

Although increased inclusion is trending nowadays, at the same time, additional efforts from the school's management, parental involvement, and teacher's efforts are required to create a welcoming environment and ensure accommodative facilities for students with SN. Continuous bullying decreases the level of integrating the students with $\mathrm{SN}$ along with students without $\mathrm{SN}$ in inclusive schools or universities. Without giving a welcoming environment and putting the students with SN at a higher risk of being victimized by bullying (Carter \& Spencer, 2006). Many external and internal factors impact bullying in inclusive schools or universities; for example, school environment, size of the school or university, outer environment nearby school, parental guidance to students, and attitudes of school administration. Schools with a high ratio of students tend to face more bullying cases compared to smaller schools (Bevilacqua et al., 2017).

Research showed that bullying is comparatively more common in inclusive segments where normal peers consider themselves as superior and target other students with any kind of disabilities in the reaction of their inclusion with them, hurt them by different means such as hitting them physically, by taunting them, by calling bad names, by giving gestures, etc.(Hong \& Garbarino, 2012).

The severity of this matter of bullying and aggressive behavior of normal peers towards students with SN and the negative social, physical, psychological, and educational impacts of bullying has emphasized the importance of studying and addressing bullying as a social health issue. Being a victim of bullying or peer aggression increases the risk of more severe physical or psychological health instability (Bonell et al., 2014). In this situation, schools' or universities' environment interventions affecting different aggression and bullying-related issues in inclusive schools have proven one of the best precautions and ways of addressing bullying-related issues in inclusive schools (Bonell et al., 2014).

Higher education is trending in Pakistan these days, and more and more students with SN are attending universities, as they want to get an education with normal peers in universities and learn skills to enhance their employability. A study is required for exploring the lived experiences of students with SN in universities in Pakistan. As being a student of an inclusive university, having any kind of physical or mental, visible, or hidden disability is a big challenge. In almost all cases, normal peers do not accept peers with SN in inclusive setups (Moriña, 2017; Griful-Freixenet, Struyven, Verstichele, \& Andries, 2017; Majoko, 2018). Also, students with SN face several issues while studying at an inclusive university. Peers without SN victimize the students with SN tease them by different means such as verbally, physically, emotionally reasons. The current study focuses on the 
daily life lived experiences of the students with (visible or hidden) disabilities studying with normal peers and facing any kind of direct or indirect bullying (Carter \& Spencer, 2006). However, there is little information on the lived experiences of students with disabilities related to bullying in universities. This study is designed to explore this phenomenon and fill the gap in the literature.

In this way, the sampled universities will be more informed and better able to provide appropriate support to all the bullying victims, to introduce the measures to overcome and control bullying in an inclusive system. The main contribution of this study has to do with the impacts of bullying on different aspects of the lives of the students with disabilities, the role of school administration to overcome bullying, parental involvement in helping their children with SN coping with bullying while studying in inclusive schools, and negative, aggressive behaviors of peers without SN towards their peers with SN studying with them in inclusive setups (Stone, 2009). In this manner, this study will add to the existing research regarding bullying-related lived experiences of the students with disabilities in inclusive universities. The new issues of bullying faced by students with disabilities and peer victimization will be highlighted and can direct the attention of the studies and experts towards reducing the risk of peer aggression and bullying in inclusive setups (Hong \& Garbarino, 2012).

\section{Methods}

The current study is a qualitative study using a phenomenological research design. This design research does not require behavioral control (Yin, 2018). This particular research design was used because it helps in developing a complex and nuanced understanding of participants' lived experiences concerning a phenomenon. Besides, it helps in "describing what all participants have in common as they experience a phenomenon" (Creswell \& Poth, 2018). The emphasis is on the description of the essence of the participants' lived experiences, not explanations or analyses (Creswell \& Poth, 2018; Tracy, 2020). Therefore, the goals of phenomenological methodology were deemed to be aligned with research questions.

The purposeful sample, utilizing a criterion sampling technique (Roulston, 2010; Patton, 2015), was selected. The criterion sampling technique involves identification of already decided specific criteria of importance, articulation of these criteria, and systematic review and study of cases that meet the criterion. The reason for undertaking criterion sampling was to generate new knowledge by comparing and contrasting different participants' lived experiences (Berndt, 2020; Denieffe, 2020).

Following criteria were used to decide the inclusion of participants in this study: The participant was a student of any private or public university; the participant had any physical, mental, emotional disability; the participant had faced minor or major bullying issues in his/her university due to his/her disability and the participant was willing for the interview, and his/her family does not have any problem with it. The demographic information of the participants is given in Table 1.

Table 1: Demographic information of the participants

\begin{tabular}{|c|c|c|c|c|c|}
\hline Participant & Gender & Age & & University & Disability \\
\hline 1 & Male & 29 & MPhil Special Education & Private & Visionary Impaired \\
\hline 2 & Male & 25 & $\mathrm{MSc}$ & Public & Physically handicapped \\
\hline 3 & Female & 24 & MPhil Special Education & Private & Visionary Impaired \\
\hline 4 & Male & 23 & MSc & Public & Deaf \\
\hline 5 & Female & 24 & $\mathrm{MSc}$ & Public & Physically handicapped \\
\hline 6 & Male & 29 & MPhil Special Education & Private & Physically handicapped \\
\hline 7 & Female & 27 & M Phil Special Education & Private & Physically handicapped \\
\hline 8 & Male & 21 & BSCS & Private & Visionary Impaired \\
\hline 9 & Male & 22 & $\mathrm{BSc}$ & Public & Partially Deaf \\
\hline 10 & Male & 24 & MBA & Public & Physically Handicapped \\
\hline
\end{tabular}

Data Collection Methods

Semi-structured interviews were conducted to collect data for this study. A semi-structured interview is a technique of data collection method in qualitative research that is based on open-ended questions related to the problem statement. Some possible questions for the interview schedule were developed based on the areas identified in the literature (Kvale \& Brinkmann, 2015). The initial draft of the interview guide was developed by the first researcher. This draft was discussed in a meeting attended by all three authors, and after discussion, the interview guide's questions were finalized. A few questions were not relevant; they were removed, whereas few questions were ambiguous; therefore, the language of these questions was amended to increase the clarity of the questions (Brinkmann \& 
Kvale, 2018). Besides, some interview questions were rearranged so that the sequence could be made logical and natural.

The interview guide was further improved by piloting it with a participant (Castillo-Montoya, 2016). As a result of this piloting, the interview guide was further revised. The language of some questions was amended. Initially, only questions were written in a sequence; then, after a discussion about the transcript of the pilot interview in a meeting of three authors, it was decided to categorize the different sections of the interview guide and then added sub-questions accordingly (Brinkmann \& Kvale, 2018; Seidman, 2019). These categories were based on the literature review and purposes of this study. After the required amendments, a pilot interview was again conducted, and then we finalized the interview guide (Castillo-Montoya, 2016).

The necessary ethical research approval for research on human subjects was obtained. The first researcher approached participants for data collection by visiting three universities in Lahore. The researcher briefed the nature of the study to the participants and asked for permission for the research to be conducted. Initially, the students with SN studying in universities, along with students without SN, were asked for their willingness to participate in interviews. They were informed that the identity of the participants would never be disclosed at any moment, ethical and emotional consideration will prioritize the participants, mainly the bullying-related experiences of the students with SN would be discussed, open-ended questions would be asked from the participants. A copy of the interview guide was provided to every student. After that, interviews were conducted with the mutual consent of the first researcher and the participants.

Two digital audio recording devices were used to record the interviews. Also, a notepad was used to take notes whenever it was deemed necessary - then a few interviews which participants given in written were read and discussed with them for further probing. All interview recordings were transcribed and translated into the English language.

\section{Data Analysis Methods}

Reflexive thematic data analysis (Braun, Clarke, Hayfield, \& Terry, 2019) was used to analyze interview data. According to this method, data analysis is conducted in six steps. Researchers conducted interviews in a semi-structured way with students with SN facing problems of being bullied in universities by the students without SN. Transcripts were read after listening to the audio recordings of their interviews and also reviewing the written responses taken from the participants while conducted the interview. Then the researcher isolated the natural meaning units and then phrases with a single meaning, and the researcher creatively used the responses of the students with SN and experiences into the final phenomenological description to form the conclusion of the research.

\section{Findings}

All participants had special needs by birth, which was the factor, they learned to live with their disabilities, but in some cases outer environment, poor behavior of others, their inability to do something due to their disabilities made them feel bad about themselves being disabled. For example, one of the participants said,

Anything that makes others behave differently towards you or make you feel unwanted is a disability. Due to the poor behavior of my female classmates, I sometimes feel a burden or unwanted in my class, in my university, and on this earth. I feel the difference between normal peers and disabled peers. Disabled peers don't interact or take part in any activity like normal peers. (Participant 3)

Also, another participant said,

Disability is not physical or mental for me. If you are not giving the same level of respect or not accepting others the way they are, this is also called disability of your character. Anything that stops you in any way is called disability. I feel the change in the behaviors of others, as many people don't talk to me. People sometimes don't interact with me, even on important things. For me, some tasks also get difficult, like class presentations, etc. (Participant 4)

At the same time, few students had normal views towards disability, and they felt normal being students with disabilities at universities. For example, the participant said, "I feel almost normal in terms of the learning point of view. I got a very big exposure here, and teachers are well qualified, and I learn a lot from my teachers" (Participant, 6). Another participant stated, "Disability is diversity. 
It is a blessing of the Almighty. You are chosen one from your Almighty to serve in this way" (Participant 1).

When the researcher asked the participants about their experiences being at $\mathrm{n}$ university, most participants stated that they had bad experiences being at a university as students with $\mathrm{SN}$, as they faced many different kinds of challenges, especially bullying by their normal peers. In some universities, they faced the issue of accessibility due to university structure which was not built according to the approved UN structure.

\section{Theme 1: Poor experiences with peers and support staffs}

Most participants were unhappy with their normal peers. Participants reported that the behavior of their teachers and support staff was acceptable and sometimes very good, but as far as the interaction with normal peers is concerned, many of the participants had bad experiences. They (normal peers) used to tease or bully them (disabled peers) in the form of making fun of their disabilities, teasing them physically, etc. Bullying directly or indirectly influenced their studies, their social interactions, and the overall stay on campus. Besides, especially with the behavior of their normal peers, they were not happy in universities. For example, two of the participants said, "I feel awkward, sometimes due to my hearing disability, when something is being discussed in groups. I feel helpless when I cannot hear, and some people make fun of it" (Participant 10). Another participant said that he had a good experience with his normal peers, but sometimes, she gets upset due to her disability. Because few of her university fellows used to tease her due to her short height and make fun of her. According to the participant,

My experience generally good with peers, but sometimes I feel it difficult and awkward due to my height abnormality and peers' reactions to it. There was a time when few students from my class and other classes used to tease and bully me, and I don't feel like going to the university due to this reason. (Participant 5)

Besides, three more participants highlighted their plight they suffered in their days in university. For example, three of them said,

I didn't find it easier to make friends, and I don't have any special friends. Because most girls want to go out to canteen or in-ground or roam around and I feel hesitant because of my dependency on others in such tasks, and they (fellow girls) also seem reluctant taking me with them, which is why I mostly just sit in my classroom and from class straight to bus after my lectures. I don't like being friends with my male class fellows, but I feel some of them are more helpful towards me as compared to female fellows. (Participant 3)

Another participant said,

I don't find it easy to make friends because there is a huge communication gap due to the barrier of my disability. Many people do not understand sign language and also don't know how to communicate with me. The communication gap is the main hindrance. Most people don't understand sign language, so they can't understand what I am trying to say or what they want to say; they can't make me understand. This is why I keep my interaction with other peers very limited and don't make friends. (Participant 4)

The third participant reported,

Most people interact with me at university. Few people don't want to interact with me due to my disability and don't answer me as they do to normal people. I feel that things sometimes, as my teacher calls other students to write something on the whiteboard or for an explanation of anything, but due to my short height, it's not possible, so teachers call other students only and ask me to write on the copy only. It sometimes decreases my confidence level. (Participant 5)

\section{Theme 2: Bullying related experience at university}

Almost every participant faced bullying of some kind in different ways. Some were the direct victims of bullying at inclusive universities, and few were being bullied indirectly. For example, one participant stated,

Bullying is abuse mentally, physically, and emotionally. I experienced a lot of bullying activities due to many students' unnecessary expectations from me while doing my classwork. Some students stole my pen/pencils, and some students wanted 
me to go out of class due to jealously because teachers appreciated me. (Participant

10)

Another participant said, "I face it (bullying) at my university. I faced weird facial expressions. Sometimes, people talk behind me" (Participant 11). Moreover, a participant stated, "It (bullying) happens sometimes and specifically in group discussions. A topic was being discussed in a group. I could not understand well, and I did sometimes ask to repeat. There, some group fellows made fun of me and started laughing" (Participant 4). One participant reported,

Yes, I face bullying from a specific group of fellows, and it hurts me. They used to call me by different bad names. Some fellows bully me by different names, they sometimes throw down my bag and then ask me to pick it up and carry myself, they laugh at my hands, and they say, 'You can't do anything, why are you studying, why don't you be a beggar instead of a student-you would be very successful? etc.' One group of my class fellows persistently bully me when no teacher was in class. I usually don't go to the playground, but in the canteen, if those students watch me sitting there, they again make fun of me, so I mostly avoid being at those places. (Participant 2)

In addition to this, one more participant said,

I only face bullying outside my class, in corridors mostly. Students misguide me in finding my class. Some students take me to some other places instead of my classroom as pretending to help me out in reaching out to my classroom. Some people intentionally hit me while passing by the corridor, etc., and also sometimes junior students pass comments while I am passing by them. (Participant 3 )

\section{Theme 3: Reporting bullying incidents to the administration, teachers, or parents}

Almost all participants who faced bullying said that they never reacted while being bullied. For example, one participant said, "I stay silent, ignore them, and walk away from those places quietly" (Participant 3). Another participant said, "I don't react; I just stay quiet and pass by, pretending I do not hear anything" (Participant 2).

Many of the participants stated that they never reported any bullying cases to the administration or teachers. For example, one of the participants said,

No, I never reported any such case; I ignore them. Once, I was hit by a student so badly I fell, and my elbow got injured. I couldn't attend my class for one week. My teacher asked me the reason and then only I told him what happened to me. He supported me and asked me to complain about this since I didn't know who that student was, so I remained silent. (Participant 3)

Only a few participants stated that they reported the bullying cases to the university administration. One of the participants said that "Yes, When I was in the first semester, I reported when fellow bullied me, then they sorted out the issue with me in front of teachers, then again they started doing the same, and I started ignoring them" (Participant 2).

Participants never discussed their bullying experiences with their parents or teachers. For example, a participant said,

No, I don't tell them (parents), but one day when I was much hurt and lock myself in the room, my mother asked me about this and wanted to discuss it, but I didn't tell her as I didn't want to make them worried about me. My parents always support me, encourage me, and never make me realize that I am disabled. I discuss this with my close friends because this all happens in front of them. They make me feel calm and ignore this type of situation. (Participant 2)

Another participant said that due to not having both parents and anyone to share with about her bullying issues, she never told anyone about bullying, "I don't have parents, and I live with my sister. I don't share anything like that with her" (Participant 3). Another participant stated that he faced some kind of bullying at his university and also asked his parents not to send him to this particular university. He wanted to go to a special education set up along with his friends, but they didn't listen to him,

I don't tell anyone, but one of my sisters is also deaf and dumb, so we both used to discuss this. If I tell them maybe, they will, but I told them I don't want to go to this 
university, but they didn't support me. They force me to go to this university because I got a scholarship. (Participant 4)

Theme 4: Negative impact of bullying on class performance

Most of the participants who faced bullying stated that it badly affected their mental health and their educational performance sometimes. For example, one of the participants said,

Bullying doesn't directly hinder my studies, but it makes me mentally upset; I feel

like skipping classes sometimes. The behavior and negative comments of other fellows upset me; in the starting days, I feel so hurt that I skip classes many times due to bullying and bad comments from my fellows. It happens when my class fellows are bullying me, and at the same time, I have any test or assignment to complete; I feel so hurt that I can't concentrate over it and skip some time. (Participant 2)

Another participant reported that bullying badly hurt him to the extent that he missed his makeup classes due to such behavior of his peers.

This kind of behavior (bullying) upset me mentally, and I am well aware of this. I am unable to perform like other normal students, and this is just because of my disability. It happened to me while taking my makeup classes on weekdays. I was bullied by students. I felt so bad that I went back home and couldn't attend my class. (Participant 3)

Theme 5: Negative impact of bullying on participation in social events

Most participants reported that they did not like attending university events, which was the result of many factors like the inability to participate in sports, games, etc. due to their disabilities, and the poor behavior of other peers making fun of them, which discouraged them from attending such university events. For example, one of the participants stated,

I do like attending these kinds of activities. Being a bit shy or introverted, I prefer staying at home most of the time. Few students from my class always bully me and make fun of me every time. They used to call me by different names (tundra, Gorilla, etc.), which is why I avoid any kind of events or activities at university. (Participant 2)

Another participant said,

No, I don't like attending any kind of leisure activity at university. Because I don't have friends to give me company or help me in moving here and there, I avoid anything at university other than my class. (Participant 3 )

Another participant stated the same kind of views,

I just hate these events because they do not develop good ethical and religious values in students. Most activities are just child playing, sort of laughing and talking with no purpose, and business-oriented with selfishness, like singing stupid songs. I like football, volleyball, badminton, but while playing, their behavior does not improve because effective moral values were not taught to my peers; they are like wild horses or animals. (Participant 10)

Only a few of the students said that they like attending university events and easily participate in co-curricular activities. They had disabilities that never hindered them from participating in university events. For example, one student said, "Yes, I like and do attend the university events; all teachers and principals are supportive and happy for me to attend these events. My teachers support me and encourage me to participate in other than class activities" (Participant 5). Another participant said that "Yes, I do, and I am part of my university club. Sometimes I do play. Teachers are supportive and encourage me to take part in such events" (Participant 10).

\section{Discussions and Conclusion}

The experiences of the students in inclusive universities were diverse. However, most of the students were not satisfied with their learning experience at universities as they faced bullying by their normal peers. They faced many different kinds of challenges like in some universities; they faced the issue of accessibility due to university structure not build according to a universal structure. Besides, especially because of the behavior of their normal peer, most participants reported that they had a poor experience with their normal peers and support staff due to their disabilities, but teachers were good and were supportive of the disabled students. Most participants were unhappy with their normal peers, who used to tease or bully them by making fun of their disabilities, teasing them physically, etc. 
Many students faced learning issues at universities due to the structure of universities, poor behavior of the support staff or other fellows, etc. Most participants did not like attending university events, which was the result of many factors like the inability to participate in sports, games, etc., due to their disabilities, also the poor behavior of other peers they made fun of them, which discourage them from attending such university events. Most participants never reacted to the bullies or reported any bullying cases to the administration or teachers, although bullying badly affected their mental health and their educational performance sometimes. Also, they never discussed their bullying experiences with their parents or teachers.

This study mainly focused on the bullying-related issues faced by students with SN in universities. We have covered different aspects related to bullying like lived experiences of bullying, reporting bullying cases, impacts of bullying on class performances, parental or teacher involvement, etc. Results showed that the majority of the participants faced bullying in different modes (physical attacks, verbal abuse, bad name-calling, etc.) many times in their universities. According to the results, it is clear that bullying severely impacts the class performance of the students and poorly causes mental health issues among victims. Bullying directly or indirectly leaves a bad impact on its victims. Comparing to a previously done similar study by (Khawaja, Khoja, \& Motwani, 2015), bad school performance and poor mental health in school adolescents were the results of abuse (bullying). This study focused on outcomes of bullying in university students, and results showed that bullying impacts the mental health of students that can sometimes lead to suicidal thoughts if not treated timely. Lack of prenatal and teacher involvement can further negatively influence young students. A study conducted by Bibi, Blackwell, and Margraf (2019) showed similar results of having poor mental health, lack of access to mental health treatment, and later on, leading to suicidal attempts due to bullying issues in students.

This qualitative study reinforces existing research that has found that bullying is one of the serious factors of our society that has been neglected badly. It is hoped that the participants' detailed descriptions in this study will guide the poor impact of bullying on our students, especially students with SN studying in higher education contexts.

\section{Implications of Research}

\section{Recommendations for policy and practice}

Based on the findings of the current research study, the following recommendations for policy and practice are made:

(1) This study has revealed an area of lack regarding students' bullying-related issues in universities. It uncovered issues of bullying and exposed that bullying is badly harming the mental health, class performance, and social life of students with SN, even at the university level. Therefore, it is recommended that in universities, bullying should be taken seriously, and it should be treated.

(2) This study raises questions about the parental and teacher's involvement in bullying; therefore, it's recommended that parents and teachers should be part of policymaking regarding bullying management in universities,

(3) The mental health of students should be taken as important as their physical health, and factors affecting badly to their mental health should be studied and treated. As shown by the research, correctional programs should be formulated and implemented in universities to address bullying cases.

\section{Suggestions for future research}

In light of the study's findings and limitations, several avenues for future research studies are suggested below:

(1) Many areas of relevance to this study remained uncovered since these areas were not targeted by the research questions, which we explored in this study. Therefore, it is suggested that future researchers can explore those areas, or they can deepen what has been investigated here in the current study. For example, future researchers can broaden current knowledge of bullying by exploring its main causes in universities.

(2) There is a need to examine how we can decrease bullying in universities and make them more inclusive.

(3) Future researchers can expand the current study by examining the poor impact of bullying on different life aspects of students. 
(4) There is a need for researchers to examine suitable intervention plans and correctional programs to overcome bullying. Though the current study's findings have highlighted the increasing bullying cases in inclusive universities, there is much to be learned about bullying in the context of Pakistani educational institutes.

\section{References}

Berndt, A. E. (2020). Sampling methods. Journal of Human Lactation, 36(2), 224-226. Retrieved from https://journals.sagepub.com/doi/abs/10.1177/0890334420906850. doi:10.1177/089033 4420906850

Bevilacqua, L., Shackleton, N., Hale, D., Allen, E., Bond, L., Christie, D., . . Jones, R. (2017). The role of family \& school-level factors in bullying \& cyberbullying: a cross-sectional study. BMC pediatrics, 17(1), 1-10.

Bibi, A., Blackwell, S. E., \& Margraf, J. (2019). Mental health, suicidal ideation, \& experience of bullying among university students in Pakistan. Journal of health psychology. doi:https://doi.org/10.1177/1359105319869819

Bonell, C., Allen, E., Christie, D., Elbourne, D., Fletcher, A., Grieve, R., . . Wiggins, M. (2014). Initiating change locally in bullying \& aggression through the school environment (INCLUSIVE): Study protocol for a cluster randomized controlled trial. Trials, 15(1), 1-14.

Braun, V., Clarke, V., Hayfield, N., \& Terry, G. (2019). Thematic analysis. In P. Liamputtong (Ed.), Handbook of research methods in health social sciences (pp. 843-860). Singapore: Springer Nature Pte Ltd.

Brinkmann, S., \& Kvale, S. (2018). Doing interviews (2nd ed.). London: Sage.

Carter, B. B., \& Spencer, V. G. (2006). The fear factor: Bullying \& students with disabilities. International journal of special education, 21(1), 11-23.

Castillo-Montoya, M. (2016). Preparing for Interview Research: The Interview Protocol Refinement Framework. Qualitative Report, 21(5).

Craig, W. M., Henderson, K., \& Murphy, J. G. (2000). Prospective teachers' attitudes toward bullying \& victimization. School Psychology International, 21(1), 5-21.

Creswell, J. W., \& Poth, C. N. (2018). Qualitative inquiry \& research design: choosing among five approaches (4th ed.). Los Angeles: Sage.

Denieffe, S. (2020). Commentary: Purposive sampling: complex or simple? Research case examples. Journal of Research in Nursing, O(0), 1-2. Retrieved from https://journals.sagepub.com/doi/ abs/10.1177/1744987120928156. doi:10.1177/1744987120928156

Graham, L. (2020). Inclusive education in the 21st Century. In L. Graham (Ed.), Inclusive Education for the 21 st Century: Theory, Policy, \& Practice (pp. 3-26). Nest NSW: Allen \& Unwin.

Griful-Freixenet, J., Struyven, K., Verstichele, M., \& Andries, C. (2017). Higher education students with disabilities speaking out: perceived barriers \& opportunities of the Universal Design for Learning framework. Disability \& Society, 32(10), 1627-1649. Retrieved from https://doi.org/10.1080/09687599.2017.1365695. doi:10.1080/09687599.2017.1365695

Hong, J. S., \& Garbarino, J. (2012). Risk \& protective factors for homophobic bullying in schools: An application of the social-ecological framework. Educational Psychology Review, 24(2), 271285.

Khawaja, S., Khoja, A., \& Motwani, K. (2015). Abuse among school-going adolescents in three major cities of Pakistan: Is it associated with school performances \& mood disorders? The Journal of the Pakistan Medical Association, 65(2), 142.

Klomek, A. B., Marrocco, F., Kleinman, M., Schonfeld, I. S., \& Gould, M. S. (2008). Peer victimization, depression, \& suicidality in adolescents. Suicide Life-Threatening Behavior, 38(2), 166-180.

Kourkoutas, E., Giovazolias, T., \& Mitsopoulou, E. (2007). Study of bullying behaviors in the Greek primary schools. Paper presented at the 2nd Counselling Psychology Conference of Geek Psychological Society.

Kvale, S., \& Brinkmann, S. (2015). Interviews: Learning the craft of qualitative research interviewing (3rd ed.). London: Sage.

Majoko, T. (2018). Participation in higher education: Voices of students with disabilities. Cogent Education, 5(1), 1542761. Retrieved from https://doi.org/10.1080/2331186X.2018.1542761. doi:10.1080/2331186X.2018.1542761 
Moriña, A. (2017). 'We aren't heroes, we're survivors': higher education as an opportunity for students with disabilities to reinvent an identity. Journal of Further \& Higher Education, 41(2), 215-226. Retrieved from https://doi.org/10.1080/0309877X.2015.1070402. doi:10. 1080/0309877X.2015.1070402

Olweus, D. (1994). Bullying at school. In L. R. Huesmann (Ed.), Aggressive behavior: Current perspectives (pp. 97-130). New York: Springer.

Olweus, D. (2001). Peer harassment: A critical analysis \& some important issues. In J. Juvonen \& S. Graham (Eds.), Peer harassment in school: The plight of the vulnerable \& victimized (pp. 320). New York: The Guilford Press.

Patton, M. Q. (2015). Qualitative research \& methods: Integrating theory \& practice. Thousand Oaks: SAGE Publications.

Rieser, R., \& Mason, M. (1990). Disability equality in the classroom: A human rights issue. London: Inner London Education Authority.

Rigby, K. J. (1998). Gender \& bullying in schools. 47-59.

Roland, E. (1989). Bullying: the Scandinavian research tradition. In D. P. Tattum \& D. A. Lane (Eds.), Bullying in schools (pp. 21-32). Stroke-on-Trent, UK: Trentham.

Roulston, K. (2010). Reflective interviewing: A guide to theory \& practice. London: Sage.

Seidman, I. (2019). Interviewing as qualitative research: A guide for researchers in education \& the social sciences (5th ed.). New York: Teachers College Press.

Stone, W. D. (2009). Bullying prevention program: possible impact on academic performance. (Unpublished doctoral dissertation), Liberty University, Virginia.

Tracy, S. J. (2020). Qualitative research methods: Collecting evidence, crafting analysis, communicating impact (Second edition. ed.). Hoboken, NJ: Wiley-Blackwell.

Yin, R. K. (2018). Case study research \& applications: Design \& methods (6th ed.). New York: Sage publications. 